\title{
Application of multivariate techniques in the evaluation of melt granulation products
}

\author{
Ana Teresa Ochoa Andrade* \\ Department of Pharmaceutical Sciences, Faculty of Chemistry, Universidad de la República
}

\begin{abstract}
In this work, principal component analysis and cluster analysis were applied as helping tools to extract useful information in the development of formulations and manufacturing processes of melt granulates. Two melt granulation processes that differ in the shear stress applied to the solid bed during melting step were designed. These processes employ equipment frequently used in the local pharmaceutical industry. The selected binders include both hydrophilic and hydrophobic excipients, which were used alone or in binary mixtures. Granulates were characterized regarding their physicomechanical properties, including their compaction behavior. The resulting tablets were also evaluated. The selected multivariate statistical methods proved to be useful in facilitating the interpretation of the collected data and the study of the properties of granulates and tablets, as well as the selection of more efficient production processes.
\end{abstract}

Uniterms: Granulates/evaluation. Tablets/evaluation. Granulates/manufacturing processes. Melt granulates/manufacturing processes. Tablets/production processes. Principal component analysis/ application. Cluster analysis/application. Pharmaceutical formulations/development. Melt granulation/ application.

\begin{abstract}
Neste trabalho, foram aplicadas as técnicas de análise de componentes principais e de análise de agrupamentos para extrair informações úteis no desenvolvimento de formulações e de processos de produção de granulados por fusão. Desenharam-se dois processos de granulação por fusão que apresentam diferenças na tensão de cisalhamento aplicada ao leito sólido durante a etapa de fusão. Esses processos empregam equipamentos frequentemente usados na indústria farmacêutica local. Os ligantes escolhidos incluíram excipientes tanto hidrofílicos quanto hidrofóbicos, utilizados de forma individual ou em misturas binárias. Os granulados foram caracterizados quanto às suas propriedades físico-mecânicas, incluindo seu desempenho no processo de compactação. Os comprimidos resultantes também foram avaliados. Os métodos de análise multivariada escolhidos provaram ser úteis para facilitar a interpretação dos dados coletados e o estudo das propriedades dos granulados e dos comprimidos, bem como a seleção de processos de produção mais eficientes.
\end{abstract}

Unitermos: Granulados/avaliação. Comprimidos/avaliação. Granulados/processo de manufaturação. Granulados por fusão/processo de manufaturação. Comprimidos/processo de produção. Análise de componentes principais/aplicação. Análise de cluster/aplicação. Formulações farmacêuticas/ desenvolvimento. Granulação por fusão/aplicação.

\section{INTRODUCTION}

Granulation continues to be an extensively practiced process in the pharmaceutical industry. Melt granulation allows the elimination of procedures such as wetting and drying, which leads to a reduction in process time and cost.

\footnotetext{
*Correspondence: A.T. Ochoa. Cátedra de Farmacotecnia, CIENFAR, Facultad de Química, UdelaR, Uruguay, Av. Gral. Flores 2124, 11800 Montevideo, Uruguay. E-mail: aochoa@fq.edu.uy
}

In this process, agglomeration is achieved by the addition of a meltable binder that is solid at room temperature and can be added at solid or molten state (Seo, Schæfer, 2001). Melt granulation offers other advantages, such as few process parameters to control during process scale-up and validation and greater patient/industry safety, as well as less environmental risks by avoiding the use of organic solvents (Thies, Kleinebudde, 1999). Moreover, by selecting a suitable binder, immediate or modified release formulations can be prepared (Thomsen, Schæfer, Kristensen, 1994; 
Passerini et al., 2002). The processes discussed in international literature mainly focus on the use of high shear mixers (Thies, Kleinebudde, 1999; Perissutti et al., 2003), extruders (Perissutti et al., 2002), and fluid bed granulators (Kidokoro et al., 2002), since these equipments have shown to be efficient in melt granulation. Unlike other studies, in the present work, two melt granulation processes that employ equipment still frequently used in the local pharmaceutical industry, such as drying ovens and medium shear jacketed mixers, were designed. These processes differ in the shear stress applied to the solid bed during the melting step. One process imposes movement of medium shear stress on the solid bed (moving bed process), while the other does not impose movement at all on the solid bed (static bed process).

Generally, several different pharmacotechnical tests are employed in the evaluation of granulates and of the tablets obtained after their compaction. As a result of the difficulties encountered in handling the great amount of data obtained from these pharmacotechnical tests, the benefit of employing tools which make this task easier becomes clearly evident and has been previously reported in literature (Gabrielsson et al., 2003; Otsuka, Mouri, Matsuda, 2003). When a number of samples are described by many variables, the variables tend to be correlated to some extent. By applying principal component analysis (PCA) to a data set, the relevant information is extracted in a few principal components, making representation and interpretation easier (Gabrielsson et al., 2003; Piggot, 1986). Meanwhile, cluster analysis (CA) seek to divide a set of samples characterized by a series of variables into several groups or clusters so that samples within the same cluster are more similar to each other than samples in different clusters. However, it is not always necessary that all samples belonging to a cluster be similar to each other. Instead, it is necessary that these samples present a high connectivity among them. More dissimilar samples belonging to the same cluster can be joined by a chain of nearest samples (Almeida et al., 2007). Despite the fact that these techniques have proved to be useful in different contexts, they are not much popular in pharmacotechnical studies.

In this context, the aim of the present study was to evaluate melt granulates using multivariate statistical tools such as PCA and CA.

\section{MATERIALS AND METHODS}

\section{Materials}

The selected meltable binders include both hydrophilic and hydrophobic excipients, which were used alone or in binary mixtures, such as: polyethylene glycol (PEG)
6000, povidone (PVP) K30, glyceryl palmitostearate (GPS), stearic acid ( STA) and glyceryl monostearate (GMS). These excipients were selected regarding the melting temperature range $\left(45-100^{\circ} \mathrm{C}\right)$ recommended as adequate for melt granulation (Thomsen, Schæfer, Kristensen, 1994), as well as regarding water affinity, safety, and low cost. PVP, though it melts over $150{ }^{\circ} \mathrm{C}$, is soluble in molten PEG and thus can also contribute to melt granulation. The solid materials to be granulated were corn starch, carbamazepine (anticonvulsivant drug, CBZ), ketoprofen (analgesic, anti-inflammatory drug, KP), and lactose monohydrate. Sodium croscarmellose (SCC), magnesium stearate and talc were used as adjuvants for the tablet formulations obtained from granulates.

The compositions of formulated granulates are shown in Table I.

\section{Methods}

\section{Granulation processes}

- Moving bed process. The solid material to be granulated and the binder are sieved through a $0.5 \mathrm{~mm}$ sieve. Solids are mixed for 15 minutes in a tumbling mixer (Turbula, Bachofen, Switzerland). The granulation is carried out by raising the temperature of the solid mixture in a laboratory scale mixer with electrical heating jacket and impeller (Erweka, SG 2, Germany), operating at $65^{\circ} \mathrm{C} \pm 5{ }^{\circ} \mathrm{C}$ and 90 r.p.m. \pm 5 r.p.m. for 15 to 20 minutes. The agglomerated mass is transferred to a glass tray, where it is kept until room temperature is reached. The granulate particle size is calibrated by an oscillating granulator through a $1 \mathrm{~mm}$ screen.

- $\quad$ Static bed process. As in the previous process and under the same operative conditions, the solid material to be granulated and the binder are sieved and mixed. The granulation is carried out by raising the temperature of the solid mixture in a drying oven (Memmert, Germany) at $70^{\circ} \mathrm{C} \pm 3{ }^{\circ} \mathrm{C}$ during 1 hour (the mixture is placed in a glass tray obtaining a depth bed of approximately $2 \mathrm{~cm}$ ). The bed is kept in the same container until room temperature is reached. The granulate particle size is calibrated by manual sieving through a $1 \mathrm{~mm}$ sieve.

As PEG, STA, and GMS were purchased as flakes, they had to be milled (cutting mill, $0.5 \mathrm{~mm}$ sieve) before the preparation of the granulates obtained using any of the two processes.

\section{Pharmacotechnical characterization of the granulates}

Particle size distributions were determined by sieve 
TABLE I - Composition of granulates

\begin{tabular}{|c|c|c|c|c|c|c|c|c|}
\hline \multirow[t]{2}{*}{$\operatorname{Assay~n}^{0}$} & \multirow[t]{2}{*}{ Process } & \multicolumn{2}{|c|}{ Material to be granulated } & \multicolumn{5}{|c|}{ Binder $(\%)$} \\
\hline & & Component & $\%$ & PEG & PVP & GPS & STA & GMS \\
\hline $\mathbf{P 2}$ & Static & Starch & 90 & 10 & - & - & - & - \\
\hline $\mathbf{P 3}$ & Static & Starch & 70 & 30 & - & - & - & - \\
\hline P4 & Static & Starch & 80 & 20 & - & - & - & - \\
\hline P5 & Static & Starch & 75 & 25 & - & - & - & - \\
\hline P6 & Static & Starch & 80 & $20^{*}$ & - & - & - & - \\
\hline P7 & Static & Starch & 80 & - & - & 20 & - & - \\
\hline P8 & Static & Starch & 70 & - & - & 30 & - & - \\
\hline P9 & Static & Starch & 70 & 30 & - & - & - & - \\
\hline P10 & Static & Starch & 70 & - & - & - & 30 & - \\
\hline P12 & Static & Starch & 75 & - & - & 25 & - & - \\
\hline P13 & Static & Starch & 80 & - & - & - & 20 & - \\
\hline P14 & Static & Starch & 75 & - & - & - & 25 & - \\
\hline P15 & Static & Starch & 90 & - & - & - & 10 & - \\
\hline P20 & Moving & Starch & 75 & - & - & - & 25 & - \\
\hline P21 & Moving & Starch & 70 & - & - & 30 & - & - \\
\hline P22 & Moving & Starch & 80 & 20 & - & - & - & - \\
\hline P23 & Moving & Starch & 80 & - & - & 20 & - & - \\
\hline P25 & Moving & Starch & 80 & - & - & - & 20 & - \\
\hline P30 & Moving & Starch & 70 & 30 & - & - & - & - \\
\hline P31 & Moving & Starch & 75 & 25 & - & - & - & - \\
\hline P32 & Moving & Starch & 75 & - & - & - & 25 & - \\
\hline P33 & Moving & Starch & 75 & - & - & - & - & 25 \\
\hline P34 & Moving & Starch & 80 & - & - & - & 20 & - \\
\hline P35 & Moving & Starch & 80 & - & - & - & - & 20 \\
\hline P36 & Moving & Starch & 80 & 20 & - & - & - & - \\
\hline P37 & Moving & Starch & 70 & 27 & 3 & - & - & - \\
\hline P38 & Moving & Starch & 75 & - & - & - & 6.25 & 18.75 \\
\hline P39 & Moving & Starch & 70 & 21 & 9 & - & - & - \\
\hline P40 & Moving & CBZ/Starch & $60 / 10$ & 30 & - & - & - & - \\
\hline P41 & Moving & CBZ/ Lactose & $60 / 15$ & - & - & - & 6.25 & 18.75 \\
\hline $\mathbf{P 4 3}$ & Moving & CBZ/Lactose & $60 / 15$ & - & - & - & - & 25 \\
\hline P44 & Moving & $\mathrm{KP} / \mathrm{Starch}$ & $30 / 40$ & 30 & - & - & - & - \\
\hline P45 & Moving & $\mathrm{KP} / \mathrm{Starch} / \mathrm{SCC}^{* *}$ & $30 / 43 / 2$ & 25 & - & - & - & - \\
\hline P46 & Moving & $\mathrm{KP} / \mathrm{Starch} / \mathrm{SCC}^{* *}$ & $30 / 42 / 3$ & 25 & - & - & - & - \\
\hline P47 & Moving & KP/Lactose & $40 / 40$ & - & - & - & - & 20 \\
\hline
\end{tabular}

* PEG milled through a $1 \mathrm{~mm}$ sieve. ** SCC functions as an intragranular disintegrant.

analysis (Retsch AS 200 control "g"). DIN-ISO 3310/1 standard sieve series for the static bed process was 125 , $180,250,355$ and $500 \mu \mathrm{m}$; and for the moving bed process, 125, 180, 250, 355, 500, 710 and $1000 \mu \mathrm{m}$. Particle mean size $\left(\mathrm{x}_{\mathrm{m}}\right), 10 \%, 50 \%$ and $90 \%$ percentiles $\left(\mathrm{x}_{10}, \mathrm{x}_{50}\right.$ and $\mathrm{x}_{90}$ ), and span were calculated. Span was calculated by the equation: $\left(\mathrm{x}_{90}-\mathrm{x}_{10}\right) / \mathrm{x}_{50}$. Bulk density was determined according to United States Pharmacopeia (USP) $<616>$ 
and tapped density was determined based on a method reported in literature (Fonner, Banker, Swarbrick, 1966). Compressibility index was calculated according to USP $<1174>$. Repose angle was determined by means of a funnel with a stopper. When the stopper is removed, the material flows, and the base and height of the cone-like pile formed are measured. Repose angle $(\alpha)$ was calculated by the equation: $\tan (\alpha)=$ height $/(0.5 *$ base $)$. Friability was assayed based on a method reported in literature (Marks, Sciarra, 1968), and the percentage of weight loss for the resulting granulates was calculated. The average of two determinations was recorded for each of the mentioned tests.

Granulates were compacted (excentric tablet press B-MT, J. Bonals, Spain) as a mean of assessing the level of success attained regarding the improvement of the physical properties required for compaction after granulation by the processes proposed in this work, using $9 \mathrm{~mm}$ concave or $12 \mathrm{~mm}$ plane round punches. Up to $5 \%$ of deviation in the tablet weight was accepted. Compacted granulates were selected among those which showed acceptable physical properties, mainly regarding flow and compactability. As required by each formulation, lubricant $(0.5 \%$ magnesium stearate or $1.5 \%$ talc) and/or disintegrant (3\% sodium croscarmellose) was added to the selected granulates in a tumbling mixer (Turbula, Bachofen, Switzerland).

The following pharmacotechnical properties of the tablets produced were studied: appearance and dimensions, weight uniformity, hardness, tensile strength, friability, and disintegration time. Friability and disintegration time were determined according to USP $<1216>$ and $<701>$, respectively. Hardness and diameter were measured with a hardness tester (Erweka TBH 220, Germany). The tablet hardness is not a valid parameter for comparing tablets of different shape and size. However, if tensile strength is calculated by equations, which depend on tablet geometry, the influence that the distinct shapes and dimensions might have is corrected (Haririan, Newton, 1999).

\section{Multivariate statistical tools}

PCA and CA were used to facilitate the evaluation of the large number of variables and of the great amount of results usually generated during the characterization of granulates and tablets.

PCA is used as a dimension reduction tool to simplify a data set, which can only succeed if the original variables are correlated (Piggot, 1986). The essential information contained in the pharmacotechnical tests performed to the granulates and their tablets is revealed by PCA, showing trends and relationships for the variables as well as for the samples.

In the present work, 35 samples and the following
11 variables were considered in the PCA of granulates: percentage of fines - defined as the fraction of granules smaller than $125 \mu \mathrm{m}$-(FINES), percentage of granules over $500 \mathrm{um}$ for static bed process or $710 \mathrm{um}$ for moving bed process (COARSE), mean particle size (MEAN), 10\% percentile (PERCEN10), 50\% percentile (PERCEN50), 90\% percentile (PERCEN90), bulk density (BULKDENS), tapped density (TAPDENS), repose angle (REPANG), compressibility index (COMPIND), and granule friability (FRIABIL). The variable identified as COARSE, which represents the fraction of granules of size over a certain limit value, is defined in different ways depending on the melt granulation process used. The difference in the limit is required due to the characteristics of the granulates produced by each process.

Twenty-four samples and the following five variables were considered in the PCA of tablets: relative standard deviation of weight (RSDWeight), tensile strength (Tstr), relative standard deviation of tensile strength (RSDTstr), friability (Friabil), and disintegration time (Disint).

In the present work, PCA was applied on raw data, considering correlation between the different variables. This selection was based on the fact that the variables were measured in different units. Kaiser criterion was applied to decide the number of components in the calculation of the PCA model.

CA is used to classify samples characterized by a series of variables into groups. Ward agglomeration criterion is a standard practice when applying CA in order to identify groups of samples of similar size. This procedure is usually used with Euclidean distances (Jacobsen, Gunderson, 1986). In the present work, CA was applied to the original data matrices of granulates and tablets in order to study the groups of samples found in the PCA plots. Results were graphically depicted under dendrogram form.

All statistical tests were performed using XL-Stat 2009 (AddinSoft, NY, USA).

\section{RESULTS AND DISCUSSION}

\section{PCA of granulates}

The first and second principal components (PC1 and PC2, respectively) of the granulate data explained $73 \%$ of the variance of the experimental data. Thus, most of the pharmacotechnical information about the granulates was provided by only two variables, instead of 11 as in the original data.

PC1 explained $57 \%$ of total variance and is positively correlated with coarse fraction, mean particle size and percentiles, while negatively with compressibility index 
and friability. Meanwhile, PC2 explained $15 \%$ of total variance and is positively correlated with tapped density. Bulk density is negatively correlated with both components, while percentage of fines (PC1 loading 0.65, PC2 loading -0.34) and repose angle (PC1 loading $0.73, \mathrm{PC} 2$ loading -0.40) are also correlated with both components, but positively with PC1 and negatively with PC2.

The following correlations among variables were found with PCA: compressibility index correlates inversely with coarse fraction, mean particle size, and $50 \%$ and $90 \%$ percentiles, which is reasonable as an increase in particle size improves the flow, while also leads to a lower compressibility index.

The correlation matrix was performed to confirm the correlations among variables which were not so evident in PCA. It was observed that compressibility index also shows less strong but significant inverse correlation with bulk density $(\mathrm{r}=-0.58 ; \mathrm{p}<0.01)$. In addition to improving flow, the enlarged size of particles also increases bulk density, decreasing compressibility index. Moreover, compressibility index directly correlates to repose angle $(\mathrm{r}=0.62 ; \mathrm{p}<0.01)$ and friability $(\mathrm{r}=0.56 ; \mathrm{p}<0.01)$ in a less strong, but significant way. The repose angle directly correlates to fines in a not very strong, but significant way $(\mathrm{r}=0.57 ; \mathrm{p}<0.01)$. This correlation is consistent with the expected decrease in flow, particularly when particle size is not increased after granulation, thus resulting in an excess of fines.

Variables and granulate samples were represented simultaneously as a biplot diagram in Figure 1. As observed in this plot, PCA showed the granulates divided in two distinct groups according to the manufacturing process: the granulates obtained by static bed process are at the left side, while at the right side are those obtained by moving bed process. In PC1 (F1) are the variables responsible for the distinction between the granulation processes, as percentage of fines and coarse, mean size, $50 \%$ and $90 \%$ percentiles, compressibility index, and repose angle, whereas in PC2 (F2) are the variables that allow the distinction among some granulates, as bulk and tapped density. Granulates obtained by static bed process show higher percentage of fines, friability, repose angle and compressibility index, as well as smaller mean particle size and lower percentage of coarse and percentiles, than the granulates obtained by the moving bed process.

PCA also revealed other trends. As binder percentage in granulate composition increases in any of the two processes, the granulates move towards higher values of PC1, which corresponds to a decrease in repose angle, compressibility index, friability and percentage of fines, and also to an increase in granule mean size, coarse frac-
Granulates: Biplot (axis F1 and F2: 72.65\%)

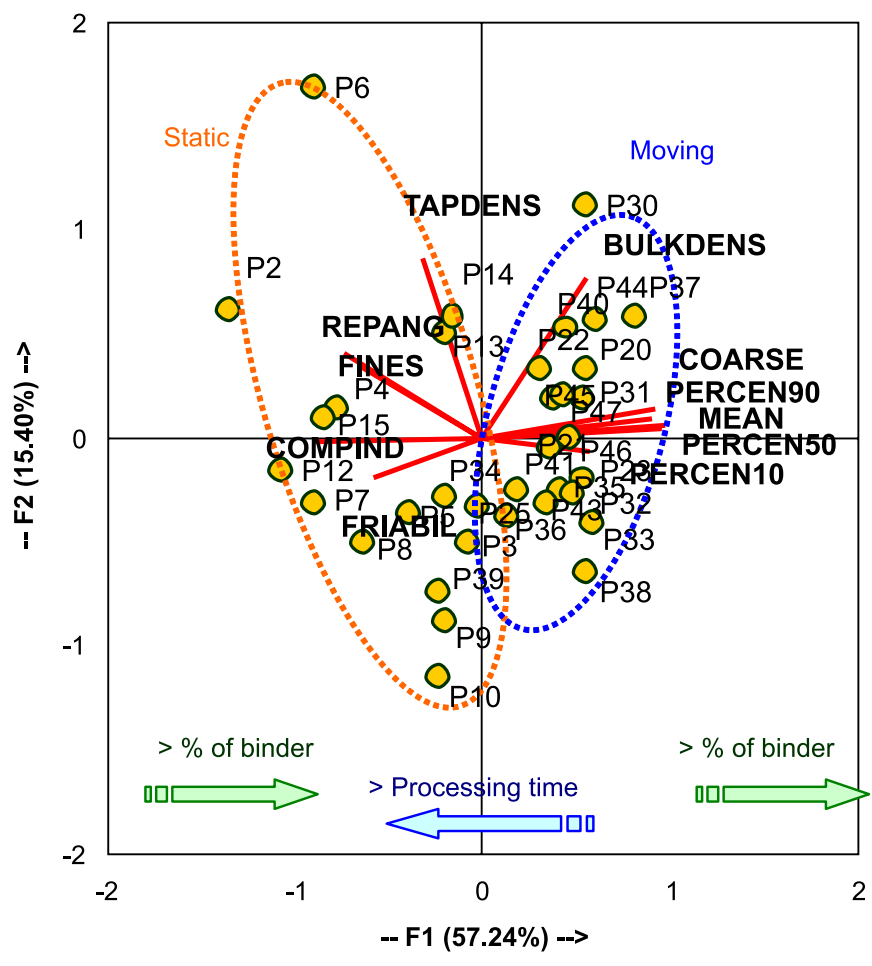

FIGURE 1 - PCA biplot of granulates for PC1 (F1) and PC2 (F2).

tion, $50 \%$ and $90 \%$ percentiles, and, to a lesser extent, in $10 \%$ percentile. The previously mentioned trends are clearly evident for binders PEG, STA, and GMS. In the case of STA, since no improvement in binder performance was observed by increasing the percentage of binder from 20 to $30 \%$ (granulates $\mathrm{P} 13$ and P10, respectively), $30 \%$ was not further used as granulating concentration with STA.

GPS showed a little erratic behavior by static bed process-P12 (25\%) located more to the left than P7 (20\%), while P8 (30\%) was located more to the right - and by moving bed process - P21 (30\%) located more to the left than P23 (20\%). Possibly, a greater number of assays with this binder would allow to elucidate its performance trend. However, the results obtained with GPS, i.e., poor improvement in granulate properties as the binder concentration is increased and the adhesion problems found during compaction, did not generate much expectation over the benefit of performing more assays with this binder.

For the binder mixture STA/GMS, which was assayed at $25 \% \mathrm{w} / \mathrm{w}$ of the granulate, the behavior was in line with the performance of each separate binder when used at the same percentage as the whole mixture.

Last, in the case of the binder mixtures PEG/PVP $(90 \% / 10 \%$ and $70 \% / 30 \%)$, which were both assayed at $30 \% \mathrm{w} / \mathrm{w}$ of the granulate, the increase in fines content 
was noticed as the rate PEG to PVP decreased. The behavior of this combination of excipients was in line with that of PEG 6000. However, the increase of PVP in the mixture at the expense of the decrease of PEG weakened the improvements the latter binder had been able to achieve in the granulates. These results are not in agreement with those reported by Gohel and Jogani in their work with PVP K30/PEG 4000 as binder for lactose and microcrystalline cellulose mixtures (Gohel, Jogani, 2003). In the present work, the temperature selected for melt granulation is not high enough for povidone fusion; therefore, the contribution of the latter excipient to the formulation and the process is expected to be accomplished by dissolution in the melted PEG. Although PVP $\mathrm{K} 30$ is soluble in PEG 6000 in several proportions, its dissolution is not fast, as confirmed in preliminary assays. It is therefore probable that the melt granulation processes proposed in the present work do not ensure enough contact time among PVP particles and the melted PEG in order to allow the complete dissolution.

The granulates are very close regarding PC2, which indicates that apparent densities did not increase after granulation. Nevertheless, it can be concluded from PCA that, for the binder PEG 6000 in moving bed process, densification certainly takes place when the binder percentage is increased, as these are the only granulates less grouped with respect to PC2, i.e., they showed larger distance in the vertical direction (from P36 to P30). In general, PCA showed that bulk and tapped densities did not provide much information to differentiate either among binders or processes, they just helped to differentiate some samples.

Regarding binder initial particle size, PCA confirmed what was observed in preliminary studies and reported in literature about the relevance of this parameter in melt granulation and also about the convenience of choosing a small initial particle size for these excipients (Schæfer, Mathiesen, 1996). The starch granulate obtained with PEG 6000 milled through a $1 \mathrm{~mm}$ sieve (P6) was located in the upper left of the biplot in Figure 1. When P6 coordinates were compared with those of P4 (produced with PEG 6000 milled through a $0,5 \mathrm{~mm}$ sieve), it was evident that, with larger binder initial particle size, percentage of fines and repose angle were increased and $50 \%$ percentile was decreased.

It was also clear in PCA that the moving bed process is the most efficient manufacturing process of the two presented in this work, as better results in granulate properties were obtained with equal percentage of binder and shorter processing time.

The trends found for each process were independent of the solid material chosen for melt granulation.

\section{CA of granulates}

As observed in Figure 2, four clusters or groups of samples were found in CA. The classification by manufacturing process defines two clusters, but a further division in each process is found; therefore, there are four clusters in total in the immediate hierarchical level (indicated in the plot by a dotted line). Clearly, the first two clusters defined by the manufacturing processes show a significantly greater linkage distance than the clusters in the immediate level. However, the latter linkage distance is still significantly greater than the distances in the following levels; moreover, the four finally defined clusters indicate a clear division regarding the percentage of binder present in the granulate composition.

From left to right, the clusters were formed as follows:

First cluster: starch granulates obtained by moving bed process with the lowest percentage of each binder, plus the granulates of carbamazepine. Thus, this cluster is formed by the granulates with the lowest compressibility index and friability, low repose angle and percentage of fines, and rather high percentage of coarse fraction, mean granule size, and $50 \%$ and $90 \%$ percentiles.

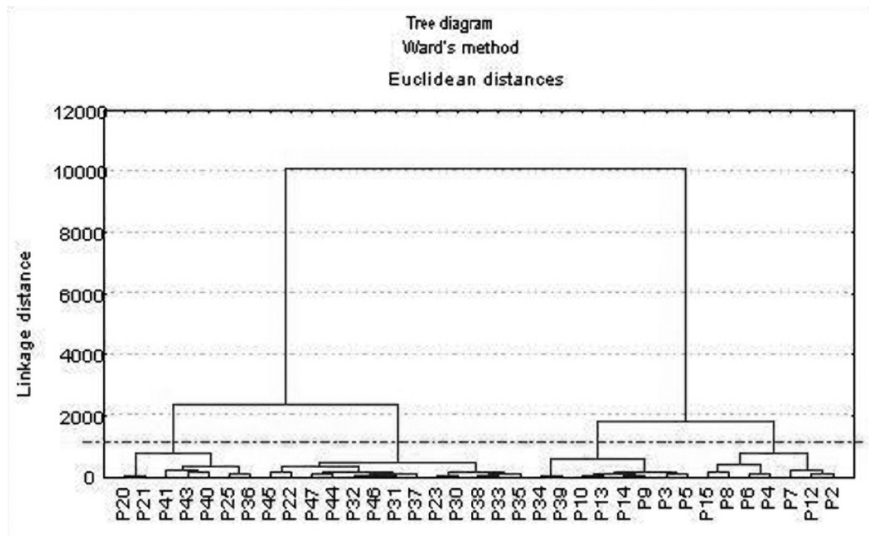

FIGURE 2 - Dendrogram of granulates.

Second cluster: granulates obtained by moving bed process with the highest percentage of each binder and their mixtures (25\% STA/GMS and 30\% PEG/PVP $[27 \% / 3 \%]$ ), plus the granulates of ketoprofen. This cluster is therefore formed by the granulates with the highest percentage of coarse fraction, mean granule size, $50 \%$ and $90 \%$ percentiles, with the lowest repose angle and percentage of fines, and with rather low compressibility index and friability.

Third cluster: starch granulates obtained by static bed process with the highest percentage of each binder, plus the granulates obtained by moving bed process with 
the poorer performances (one with $30 \%$ of PEG/PVP $[21 \% / 9 \%$, mixture with the lower percentage of PEG] and another one with $20 \%$ of STA). Therefore, this cluster is formed by the granulates with rather high repose angle, compressibility index, percentage of fines, and friability, and also with low percentage of coarse fraction, mean granule size and percentiles.

Fourth cluster: granulates obtained by static bed process with the lowest percentage of each binder, plus the granulates with GPS even at the highest concentration $(30 \%)$. Thus, this cluster is formed by the granulates with the highest percentage of fines, repose angle, compressibility index and friability, and with the lowest percentage of coarse fraction, mean granule size, and $50 \%$ and $90 \%$ percentiles.

\section{Compaction behavior of granulates}

Tablets of proper aspect, mechanical resistance and disintegration time, and that comply weight uniformity as well as the corresponding assay of active content, dose uniformity and dissolution, in the case of tablets containing active ingredients, were obtained from several granulates.

\section{- PCA of tablets}

The first two principal components (PCs) or factors (F) described $68 \%$ of the variance of the tablet data. Once again, most of the pharmacotechnical information was accounted for in the multivariate analysis, indicating that it was successful for tablets too.

The loading plot for PCs 1 and 2 (or F1 and F2) for each variable, as well as for the tablet samples (score matrix), are represented simultaneously as a biplot diagram in Figure 3 . PC1 is positively correlated to the disintegration time and tensile strength, and negatively correlated to friability. PC2 is positively correlated to the relative standard deviation (RSD) of tensile strength. RDS of weight is correlated to both PCs.

The correlations among variables commented hereafter were found by means of PCA. Tensile strength directly correlates with disintegration time. As in the case of granulates, the correlation matrix was done in order to confirm the correlations among variables which were not so evident in PCA. As a result, it was found that the tensile strength inversely correlates with the friability in a not very strong, but significant way $(\mathrm{r}=-0.42 ; \mathrm{p}<0.05)$.

As shown in Figure 3, several trends were revealed by PCA. As binder percentage in the formulation of a granulate obtained by either process is increased, the tablets move towards higher values in PC1, corresponding
Tablets: Biplot (axis F1 and F2: $67.53 \%$ )

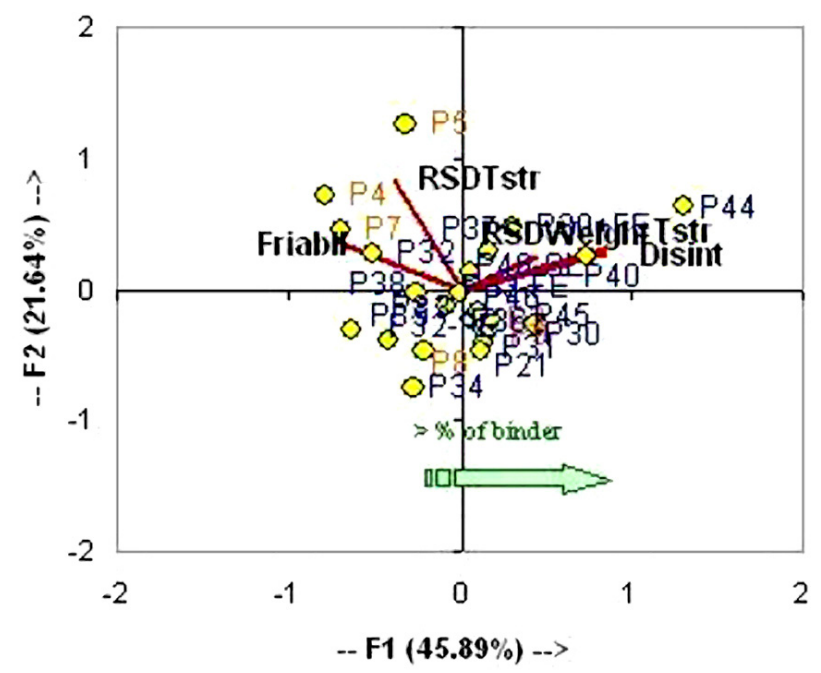

FIGURE 3 - PCA biplot of tablets for PC1 and PC2.

to lower friability, and, to a lesser extent, lower RSD of the tensile strength, but also higher tensile strength and disintegration time of the tablets. Although a slight increase in the RSD of the weight is evident, the results are still acceptable, which is consistent with the fact that, when the binder percentage is increased, the flow of the granulates is improved.

The above mentioned trends are clearly evident for the granulating excipients PEG 6000, GPS, and GMS. In the case of STA, when concentration is increased from $20 \%$ to $25 \%$ (from P34 to P32) practically no changes take place, as observed by their proximity in PC1, showing the same behavior as the granulates of this excipient. For binder mixtures PEG/PVP and STA/GMS, tablets general behavior was in line with the results obtained with each separate binder when used at the same percentage as the whole mixture, following the same trend already observed in the granulates. The mixture STA/GMS instead, shows better behavior regarding lamination and adhesion to punch surface than the excipient STA alone (Table II).

As in first instance, different granulates required different external phases for compaction, PCA was also used to study the effect of the presence or absence of magnesium stearate and sodium croscarmellose on the compaction behavior of granulates. In every pair of tablets formulated with and without these excipients, each tablet is very close to its corresponding partner regarding PC1 (Figure 3). Therefore, PCA contributed to conclude that these excipients, when used as lubricant and disintegrant respectively, did not affect the results and were after all dispensable. 
TABLE II - Compaction behavior of granulates

\begin{tabular}{ll}
\hline Granulates & Performance in compaction \\
\hline P14, P14-FE & Uniform flow, excessive adhesion to punch surface \\
P21, P32, P32-FE, P34, P35 & Uniform flow, lamination, adhesion to punch surface \\
P7, P8 & Uniform flow, lamination \\
P33, P33-FE, P38 & Uniform flow, tendency to laminate and adhere to punch \\
P4, P5 & Uniform flow, tendency to laminate \\
P45, P46 & Uniform flow, tendency to adhere to punch surface \\
P3, P9, P30, P30+FE, P31, P36, P37, P40, P44 & Smooth surfaces, uniform flow, good compactability \\
\hline
\end{tabular}

-FE: without external phase

$+\mathrm{FE}$ : with magnesium stearate as external phase

- CA of tablets

Five clusters were found in CA (see Figure 4). From left to right the clusters were formed as follows:

First cluster: tablets of ketoprofen granulates obtained by moving bed process with the highest percentage of PEG 6000. These are the tablets with the highest tensile strength and disintegration time, and the lowest friability.

Second cluster: tablets of ketoprofen granulates with low percentage of PEG 6000 and tablets of carbamazepine granulates with PEG 6000 obtained by moving bed process. These are tablets with high tensile strength and disintegration time, and low friability.

Third cluster: tablets of starch granulates obtained by static bed process with GPS, plus the tablets of granulates obtained by moving bed process with STA and with the lowest percentage of GMS. These are the tablets with the lowest disintegration time and tensile strength, and high friability.

Fourth cluster: tablets of starch granulates obtained by static bed process with the highest percentage of PEG 6000 , plus tablets of granulates obtained by moving bed process with GPS, PEG 6000 and PEG/PVP. These are the

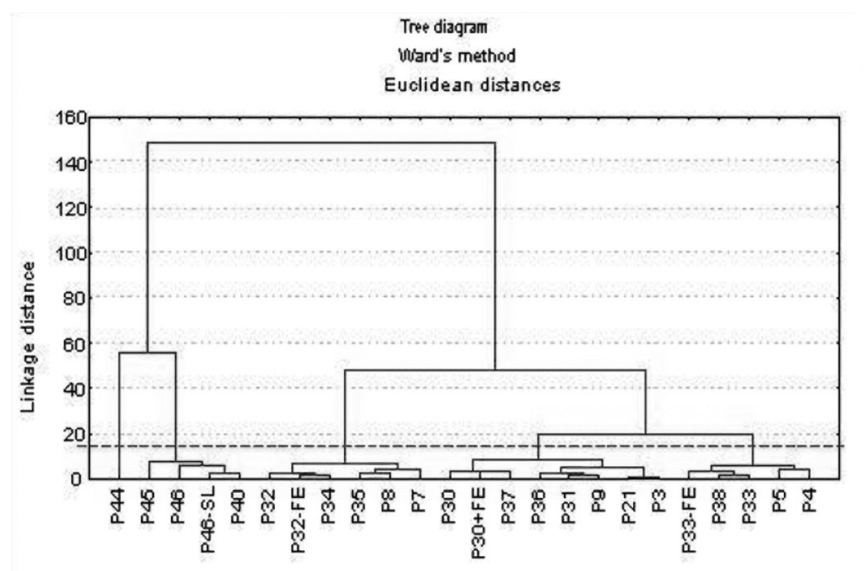

FIGURE 4 - Dendrogram of tablets. tablets with intermediate values of disintegration time and tensile strength, and low friability.

Fifth cluster: tablets of starch granulates obtained by static bed process with low percentage of PEG 6000, and tablets of granulates produced by moving bed process with high concentrations of GMS and STA/GMS. These are tablets with low disintegration time and tensile strength, and high friability.

\section{CONCLUSIONS}

PCA showed the trends and relationships among variables and samples, revealed the groupings of granulates according to the manufacturing process, as well as the greater efficiency of the moving bed process, as this process provided better results than the static bed process with equal percentage of binder and shorter processing time. PCA also contributed to conclude about the relevance of small binder initial particle size and the use of lubricant and disintegrant excipients in formulation steps. Moreover, PCA allowed the representation of the relationships among all variables in only one biplot diagram and it also minimized the loss of information, as all variables were kept in the analysis.

CA complemented the information generated by PCA, supporting the advantage in efficiency of the moving bed process over the static one, as well as the influence of the concentration of binder employed.

The results regarding the more efficient moving bed granulation process, the relevance of binder initial particle size in granulation and the use of external phase excipients for compaction were found in accordance with expectations, showing the ability of this approach to aid formulation and manufacturing also in the case of melt granulation. Therefore, multivariate statistical methods proved to be useful to facilitate the interpretation of the obtained data. Hence, it can be concluded that the employ- 
ment of PCA and CA optimize the study of the properties of melt granulates and tablets, and the selection of more efficient production processes.

\section{REFERENCES}

ALMEIDA, J.A.S.; BARBOSA, L.M.S.; PAIS, A.A.C.C.; FORMOSINHO, S.J. Improving hierarchical cluster analysis: A new method with outlier detection and automatic clustering. Chemometr. Intell. Lab., v.87, n.2, p.208-217, 2007.

FONNER JR, D.E.; BANKER, G.S.; SWARBRICK, J. Micromeritics of granular pharmaceutical solids I. Physical properties of particles prepared by five different granulation methods. J. Pharm. Sci., v.55, n.2, p.181-186, 1966.

GABRIELSSON, J.; LINDBERG, N.; PALSSON, M.; NICKLASSON, F.; SJÖSTRÖM, M. Multivariate methods in the development of a new tablet formulation. Drug Dev. Ind. Pharm., v.29, n.10, p.1053-1075, 2003.

GOHEL, M.C.; JOGANI, P.D. Exploration of melt granulation technique for the development of coprocessed directly compressible adjuvant containing lactose and microcrystalline cellulose. Pharm. Dev. Technol., v.8, n.2, p.175-185, 2003.

HARIRIAN, I.; NEWTON, J.M. Tensile strength of circular flat and convex-faced Avicel PH102 tablets. DARU J. Pharm. Sci., v.7, n.3, p.36-40, 1999.

JACOBSEN, T.; GUNDERSON, R.W. Applied cluster analysis. In: PIGGOT, J.R. Statistical procedures in food research. London: Elsevier Applied Science, 1986. p.361-408.

KIDOKORO, M.; HARAMIISHI, Y.; SAGASAKI, S.; SHIMIZU, T; YAMAMOTO, Y. Application of Fluidized Hot-Melt Granulation (FHMG) for the Preparation of Granules for Tableting; Properties of Granules and Tablets Prepared by FHMG. Drug Dev. Ind. Pharm., v.28, n.1, p.67-76, 2002.

MARKS, A.M.; SCIARRA, J.J. Effect of size on other physical properties of granules and their corresponding tablets. $J$. Pharm. Sci., v.57, n.3, p.497-504, 1968.
OTSUKA, M.; MOURI, Y.; MATSUDA, Y. Chemometric evaluation of pharmaceutical properties of antipyrine granules by near-infrared spectroscopy. AAPS PharmSciTech, v.4, n.3, art. 47, 2003.

PASSERINI, N.; ALBERTINI, B.; GONZALEZ-RODRIGUEZ, M.L.; CAVALLARI, C.; RODRÍGUEZ, L. Preparation and characterisation of ibuprofen-poloxamer 188 granules obtained by melt granulation. Eur. J. Pharm. Sci., v.15, n.1, p.71-78, 2002.

PERISSUTTI, B.; NEWTON, J.M.; PODCZECK, F.; RUBESSA, F. Preparation of extruded carbamazepine and PEG 4000 as a potential rapid release dosage form. Eur. $J$. Pharm. Biopharm., v.53, n.1, p.125-132, 2002.

PERISSUTTI, B.; RUBESSA, F.; MONEGHINI, M.; VOINOVICH, D. Formulation design of carbamazepine fast-release tablets prepared by melt granulation technique. Int. J. Pharm., v.256, n.1/2, p.53-63, 2003.

PIGGOT, J.R. Statistical procedures in food research. London: Elsevier Applied Science, 1986. p.185-191.

SCHÆFER, T.; MATHIESEN, C. Melt pelletisation in a high shear mixer. IX. Effects of binder particle size. Int. J. Pharm., v.139, n.1/2, p.139-148, 1996.

SEO, A., SCHÆFER, T. Melt agglomeration with polyethylene glycol beads at a low impeller speed in a high shear mixer. Eur. J. Pharm. Biopharm., v.52, n.3, p.315-325, 2001.

THIES, R., KLEINEBUDDE, P. Melt pelletisation of a hygroscopic drug in a high shear mixer. Part 1. Influence of process variables. Int. J. Pharm., v.188, n. 2, p.131-143, 1999.

THOMSEN, L.J.; SCHÆFER, T. Y.; KRISTENSEN, H.G. Prolonged release matrix pellets prepared by melt pelletization. II. Hydrophobic substances as meltable binders. Drug Dev. Ind. Pharm., v.20, n.7, p.1179-1197, 1994.

Received for publication on $25^{\text {th }}$ February 2011 Accepted for publication on $08^{\text {th }}$ July 2011 
